\title{
National Identity and Migration in an Emerging Gateway Community
}

\author{
Jennifer Byrne \\ Department of Political Science, James Madison University, Harrisonburg, VA 22807, USA; byrneje@jmu.edu; \\ Tel.: +520-245-0347
}

Received: 15 March 2018; Accepted: 15 April 2018; Published: 26 April 2018

check for updates

\begin{abstract}
This paper examines how conceptions of national and local identity influence reactions to migration in the Shenandoah Valley, a rural location in Southwest Virginia with unique demographic characteristics. While Shenandoah Valley residents have been predominantly non-Hispanic whites of European descent, a recent visible influx of Hispanic laborers, a higher than national average Muslim population, a history of refugee resettlement and the migration of urbanites from Northern Virginia have made the Valley one of the most diverse locations in the state of Virginia today. Using a qualitative methods approach with both apriori and emergent coding, I offer some insights as to how a traditional ethnic and civic framework of national identity and emergent themes of local identity, including family values and traditionalism, influence reactions to the changing demographics in this rural community.
\end{abstract}

Keywords: national identity; immigration; gateway communities; Shenandoah Valley

\section{Introduction}

Virginia currently has the 15th largest immigrant population in the country, and as the state with the fourth largest share of the foreign-born Latino population, it can be considered part of a trend of Latino immigrant settlement in the South (Krogstad and Keegan 2014; Stepler and Hugo-Lopez 2016). Although Hispanics are the fastest growing population of immigrants, the largest percentage of immigrants living in Virginia are from Asian countries. Demographics in the state have transformed at a remarkable pace; in 19701 in 100 residents in the state were foreign born while today that figure is one in nine (Bearinger 2014). While most of this change has affected the bustling metropolitan regions of Northern Virginia, where 2/3 of all foreign-born Virginians live, the Shenandoah Valley, a geographic and cultural region in Western Virginia, has undergone quite a demographic transformation. While Southwest Virginia is home to less than $4 \%$ of the foreign-born population in Virginia, the Shenandoah Valley, has a visible influx of migration from refugee resettlement (including a higher than national average Muslim population), labor-driven immigration from Central America, and domestic transplants from surrounding states and urban areas. The school system is one of the most diverse in the state with more than 50 languages spoken and 40 countries represented among its enrolled students. In the face of unprecedented growth in a region that is quickly becoming a new gateway city for many immigrants in America, how will these newcomers be received? In this project, focus group meetings with local civic organizations in Harrisonburg City/Rockingham County and individual interviews with residents across the Shenandoah Valley are conducted to determine how conceptions of national and local identity influence attitudes toward migration in the Shenandoah Valley. Of particular interest, is whether common conceptions of national identity in the civic versus ethnic framework apply to this area and what other conceptions of identity may exist that shape attitudes towards migration. 


\section{American National Identity and Migration}

Throughout much of the literature on this topic, conceptions of national identity are seemingly characterized by a schizophrenic dichotomy. A common theme is the recognition that while identification with the nation unites one to fellow nationals and serves as a source of integration, it is also a mechanism that separates these group members from others. This division is often accompanied by negative feelings toward non-group members, as social identity theory predicts, and recent empirical work on the link between ethnocentrism and a host of restrictive policy attitudes suggests (Kinder and Kam 2010). De Figueiredo and Elkins (2003) distinguish between nationalism and patriotism as concepts in their work, and this distinction leads them to the conclusion that highly patriotic individuals show no more prejudice towards immigrants than an average citizen. In contrast, high levels of nationalism are associated with feelings of national superiority, which is associated with prejudicial attitudes towards immigrants. Citrin et al. (2001) examine this dichotomy in the context of a more restrictive nativist, or ethnic, conception of national identity and less restrictive assimilationist, civic conception of national identity. While both conceptions are associated with the positive aspects of national identity (a mechanism to unite all nationals), ethnic conceptions are thought to stress higher levels of antagonism towards outgroups.

An ethnic conception of national identity emphasizes bloodlines, ancestry and cultural traits acquired during early socialization. This element of national identity "links country of birth, extended residence and dominant religious faith with being a member of the in-group (a right usually conferred by birth or extended residence)" (Jones and Smith 2001a, 2001b). Ingroup members who subscribe to a strong ethnic national identity will value cultural conformity and national unity. Thus, national identity is associated with what Roshwald (2006) labels "ostensibly fixed cultural markers" (i.e., hard to change attributes acquired in infancy such as one's mother tongue and native accent), and Wilcox (2004) characterizes as a national culture as consisting of language, religious beliefs, customs, and moral values. Smith (1997) labels ethnocultural Americanism, at its extreme, nativism, and ethnoculturalism is most closely linked to the notion that an American is a white, Anglo-Saxon, English-speaking protestant with Northern European ancestry (see also Higham 1988; Schildkraut 2003, 2007, 2011). Thus, individuals with strong ethnocultural identities are less likely to embrace immigrants, particularly the immigrants of today, who arrive predominantly from Latin America and Asia. Ethnoculturalism as a tradition of American identity is not only linked to more negative attitudes towards immigrants but is expected to be associated with the most extremist and nativist of the negative attitudes. Since 9/11, higher identification with the ethnocultural dimension of identity has been linked to support for the restriction of rights to peoples of particular religions and ethnicities, including documented evidence of the role that ethnoculturalism plays in fostering support for the internment of Arab-Americans, racial profiling, and heightened levels of immigrant resentment (Davis and Silver 2004; Lichtblau 2003; Malkin 2004; Schildkraut 2002, 2009, 2011). While the ethnocultural dimension of identity may be the least embraced publicly, it remains a part of the framework of American identity and its staying power has been well documented (Byrne 2011; Byrne and Dixon 2016; Citrin and Duff 2001; Gerstle 2001; Schildkraut 2003, 2005, 2007, 2009, 2011; Smith 1997).

Civic conceptions of national identity, in contrast, are based "in a common loyalty to a territorially defined state and rooted in a set of political rights, duties, and values shared by citizens of that state, regardless of their ancestry and of the non-political aspects of their cultural heritage" (Roshwald 2006, p. 254). Proponents of the civic dimension place more importance on respect for political institutions and the political values on which they are based, acquiring citizenship, and a feeling of attachment to the nation (Jones and Smith 2001a, 2001b). These characteristics are more open for immigrants to acquire (though not necessarily easily acquired) when they migrate to a country than the rigid, often fixed, cultural markers associated with ethnoculturalism (Hjerm 2004; Heath and Tilley 2005; Lewin-Epstein and Levanon 2005; Citrin et al. 2001; Schildkraut 2005). In America, these institutions are inherently connected to liberal ideals, including notions of individual liberty, democratic principles, equality, and freedom (Salins 1998). According to scholars such as Banning (1986); Smith (1997); 
Schildkraut $(2005,2007,2009,2011)$, the civic notions of identity also embody the idea of being a responsible, active citizen where members of a community act on its behalf. While both conceptions of identity set boundaries between ingroup and outgroup members, the ethnic/cultural dimension is viewed as a less consensual set of criteria for national membership in comparison to dimensions based on civic identity.

Throughout the literature, civic identity is cast in a favorable light-it provides the "glue" that holds the mosaic of a culturally plural nation together in the absence of ethnic ties (Citrin et al. 2001; Hjerm 1998; Jones and Smith 2001a, 2001b; Pickus 1998). Moreover, rather than simply allowing for or being flexible enough to accommodate cultural pluralism, civic ideals are necessary if people are to move beyond their narrow ethnic loyalty and facilitate an environment where native citizens respect of the cultural differences of immigrants (Pickus 1998). A civic identity is deemed necessary to ensure social justice, realize liberal ideals, and sustain cultural pluralism. Even those that do not fully embrace the virtues of civic notions of identity acknowledge that civic national identity is in principle, more ethnically inclusive (Wilcox 2004). This sense of shared national identity among citizens is derived from "the realization of important liberal ideals and practices" and a commitment to the "political ideals and principles upon which the polity is founded" (Wilcox 2004, p. 569). These notions of kinship are formed by what Roshwald (2006 labels "ideological ancestors" such as the Founding Fathers of the US, providing a link through metaphorical blood or "figurative kinship" rather than by lineage. To this end, liberal conceptions of American national identity are distinctly civic rather than ethnic (Citrin et al. 2001; Huntington 1981).

The civic-political notion of identity is characterized as both "ideological and affective" (Pickus 1998). While it embodies a commitment to liberal ideals, it also "requires some felt sense of communal obligation, some feeling of responsibility derived from a perception of shared history and fate. National identity includes a reverential element, an emotional attachment to the polity" (Pickus 1998, p. 30). Thus, the idea of feeling American of thinking of oneself as an American, (one of "us" versus one of "them"), a marker of identity noted by thinking of oneself as an American, is also characteristic of the civic/political dimension of American national identity (Schildkraut 2011). Salins (1998) likens the process of adopting a civic national identity to a religious conversion, as both require the acceptance of basic foundational principles that is accompanied by an emotional attachment. The culmination of the citizenship process with the swearing in and oath of affirmation, is symbolic of this transformation of identity (Pickus 1998). Thus, a civic national identity links foundational political principles, such as liberalism and current political practices, with an emotional attachment to the polity and the people that share it.

While civic/political nationalism seems robust, civic notions of identity also embody a commitment to the polity itself that is greater than the sum of individual rights and liberties or an individual emotional affirmation. In the literature, civic republicanism is a separate dimension of national identity that emphasizes the responsibilities and duties of citizenship. This dimension of American national identity is theoretically distinct from the aforementioned civic/political (or liberal) dimension of national identity because while this dimension emphasizes a commitment to liberal principles and institutions, the civic/republican dimension of national identity emphasizes a commitment to the public good. In the literature, the public good as the motivation of individuals to "labor for the good of the state" while Schildkraut $(2007,2011)$ characterizes civic republicanism as an involvement in political and social life. This means that members of the nation see the community as an integral part of their identity, and "pursue ends that will serve the public good" (p. 599). Recent empirical work by Schildkraut (2011) has supported the bi-dimensionality of civic conceptions of American identity, and finds that higher support the civic republican dimension is negatively associated with support for a number of ethnic and racially based policies, including racial profiling, official English policies, and the extension of benefits to legal immigrants, even when other civic based notions of identity, namely civic/republicanism, are positively related to such policies. 
Higher levels of both social tolerance and political tolerance, however, are expected to be associated with the civic/republican dimension of national identity. High levels of this dimension should have the highest integrative capacity, as it preserves respect for diverse cultures and preserves immigrants' access to public life. A civic/republican identity is more focused on political involvement and civic engagement; involvement in the community provides a bond that links members together. Thus, civic/republican notions of identity are surely civic in nature rather than ethnic but are distinct enough from civic-political or liberal notions of identity to characterize a separate dimension in a multi-dimensional framework of American national identity.

In summation, an ethnic/cultural dimension of national identity is expected to foster the most negative attitudes towards immigrants and is expected to have the starkest effects on extremely negative attitudes. Civic notions of identity are less likely to be associated with clear-cut negative attitudes, but, of all three dimensions of identity, the civic/republican dimension of national identity is expected to be associated with the most positive attitudes towards immigrants. Civic notions of identity, particularly civic/republicanism, are expected to counter balance the propensity towards negative attitudes fostered by ethnocultural identity.

Previous research has shown that national identity matters and that it is multidimensional. This project can fill in current gaps in several meaningful ways. Current survey data can shed some light on general trends in attitudes. However, if Americans embrace multiple conceptions of identity, some of these dimensions might be more salient than others at the local level. Residents in local areas may define these dimensions quite differently or use different criteria altogether to define their identity. While this tri-chotomous framework for studying and conceptualizing American national identity is associated with clear expectations about how national identity is linked to attitudes towards immigrants, the empirical findings have been mixed at best. Though ethnoculturalism is consistently linked to more negative attitudes, the effects of the civic dimension are not clear in the literature. Contrary to theoretical expectations, at times the civic dimension has been associated with negative attitudes towards immigrants (Byrne 2011; Byrne and Dixon 2016; Citrin et al. 2001; Schildkraut 2005, 2011; Smith 1988). This multidimensional framework has also been controversial in the literature as there is no consensus on the degree to which these categories are mutually exclusive. Miller (2000) views these concepts as entirely exclusive and argues that they cannot be combined; consequently, if an individual emphasizes ethnic notions of national identity, civic conceptions of identity are automatically rendered less important. Conversely, Brubaker (2004) contends that there are several, interrelated ways to conceptualize national identity based on ethnic and civic considerations, and that these elements are used simultaneously to attribute or deny group membership in the nation. Using in-depth interviews and focus groups can give researchers a sense of whether the debate over the degree of exclusivity of the dimensions and the potential for interaction between them is one that can generate useful hypotheses that can be empirically tested.

In this study, respondents are given a chance to clarify and discuss the concept of Americanism and how this informs their expectations of new residents (both immigrants and domestic migrants) in their own words when participating in a focus group or interview. Local governments are the primary vehicles to open new pathways to integration for immigrants through programs involving English language education, service provision, and programs targeted at civic participation and orientation towards naturalization (Singer 2008). As there is no "one size fits all" approach to integration, attention at the local level is merited (Morse and Ray 2008). These conceptions have been tested the national level and we know that they have some explanatory power, but how do they operate at the micro-level? Are attitudes in small towns in the rural South largely shaped by macro-level frameworks of ethnic and civic based national identity? Current research has shown us that explaining the behavior of people in regions such as the Midwest or deep South based on values or economics is incomplete and that group identity may play a more dominant role in explaining political attitudes (Cramer-Walsh 2012; Hochschild 2016). Thus, I would argue that it is essential to examine conceptions of national and local 
among residents in the Shenandoah Valley, and draw some initial conclusions about how identity affect support for migration.

\section{The Shenandoah Valley as a New Gateway}

This research project focuses on the reception of immigrants in non-traditional gateway areas. Established patterns of immigrant settlement have given way to new trends in settlement, replacing traditional bulwarks of immigrant-receiving gateways with newer destinations. While many of these new 21st century gateways are metropolitan areas, previously homogenous suburban and rural areas are beginning to receive their share of new arrivals. Noted anthropologist Zarrugh (2007, 2008, p. 1468) contends that, "The small city of Harrisonburg, located in the Central Shenandoah Valley of Virginia, is perhaps the premier example of this new pattern of change." Perrine (2017) notes that amid nationalist claims that mixing ethnicities and religions will inevitably result in conflict, Harrisonburg stands as a model of "international coexistence".

The state of Virginia, along with other southern states including North Carolina, Arkansas, and Georgia, is experiencing rapid growth of its immigrant population. The small town of Harrisonburg, in particular, has undergone quite a transformation. According to the 1990 Census, the non-Hispanic white population was roughly $85 \%$ of the total population, but in 2005 this declined to $75 \%$. Concurrently, the Hispanic population has grown from $0.9 \%$ in 2000 to $13 \%$ in 2006 . Though Harrisonburg has had a Hispanic presence since the 1960's, much of the growth of the Hispanic population has occurred in the last ten years; therefore, it can be classified as a pre-emerging gateway location (Singer et al. 2008) ${ }^{1}$. Local advertising once promoted the homogenous demographics of the city, highlighting its $99.2 \%$ American-born and $93.7 \%$ white population, yet today, the area represents one of the largest, and diverse (with Spanish speakers represented from 14 different countries) proportion of Hispanic residents in the state. The changing nature of the population is reflected in the community by an increasing number of Latino-owned and immigrant-oriented businesses (Zarrugh 2008). It is expected that the Hispanic presence will continue to grow because of the availability of jobs in the local agricultural industry. In addition, Zarrugh's research demonstrates that the social networks established by previous immigrants continue to draw new friends and relatives to the area (Zarrugh 2008).

Moreover, Harrisonburg is home to the Refugee Resettlement Center, which introduces new residents to this community from all over the world. Harrisonburg is one of 400 resettlement locations, designated by the US Department of State, largely due to the strong economic growth of the South, availability of low-skilled employment, relatively low cost of living, and the large network of churches, which serve as sponsors to new arrivals (Zarrugh 2008). Relatively few Latin-American refugees have been relocated to Harrisonburg, though many nationalities are represented, including Congolese, Eritreans, Russians, Bosnians, Turks, Cubans, Iraqi Kurds, and Afghans. Refugee resettlement has also been a catalyst for a sizeable and growing Muslim population in the Shenandoah Valley; Harrisonburg alone is home to 4000 residents of residents who identify as Muslim, making Muslims nearly $10 \%$ of the overall population in this small city (comparatively, Muslims make up about $1 \%$ of the population nationwide). Given the high volumes of refugees that are resettled in the Valley, it is not surprising that a recent study by the Brookings Institution highlighted Harrisonburg and the surrounding Rockingham County as among the top ten areas impacted nationwide with the highest share of refugees by President Trumps' executive order limiting refugee migration to the United States (Berube 2017). As a further testament to the rapidly growing diversity in a relatively short time span, consider the fact that Harrisonburg is home to the state of Virginia's largest ESL program and one of its most diverse public-school districts, serving over $40 \%$ of the student population, who speak 57

1 (Singer et al. 2008) define a pre-emerging gateway as a place where immigrant populations have grown very rapidly over the last ten years and are likely to continue to grow as immigrant destinations. 
different languages, and represent 46 countries. This fact becomes even more remarkable when you consider that during the 1993-1994 school year, just under 5\% of students used this program. Due to the combination of social networks established by immigrant "pioneers", a network of churches, the refugee resettlement program, and agricultural industry, roughly $16 \%$ of the population of this small town is now foreign-born, higher than the state of Virginia's overall foreign-born population. In addition, Harrisonburg has immigrants that come from all regions of the world, and its immigrant population is not predominantly represented by one country of origin (Price and Benton-Short 2007). Thus, it can be considered a "hyperdiverse" emerging gateway city, making it an ideal location to conduct a research project on how national identity is conceptualized at the local level in this context. While Harrisonburg has some unique features and demographics, a recent report from the Carsey Institute notes that as evidence of the decentralization of immigrant settlement occurs, more rural counties with large recent influxes of immigrants have emerged throughout the country (Jensen 2006). This report suggests that the "the context of reception-receptivity of rural and small towns to new immigrants-can vary greatly from place to place and can have significant impacts on the ability of communities to cope and immigrants to assimilate and prosper," (Jensen 2006, p. 5). This underscores the importance of research in these local communities, particularly an in-depth qualitative, case study approach.

\section{Data and Methods}

\subsection{Data Collection and Analytical Tool}

This project relies on data collected from three focus groups within the Harrisonburg/Rockingham community, 24 semi-structured interviews with individuals living in various communities within the Shenandoah Valley, and meet-ups with local groups at events over a period of three years. The focus groups and interviews were conducted and facilitated by myself with the assistance of undergraduate research assistants from late 2012 through early 2015. As the purpose of this study was not to generalize in a statistical sense but to understand a specific local community with a unique population, I did not use a random sampling technique. Local community civic organizations were identified using purposive sampling and snowball techniques. Civic organizations, defined by Skocpol and Fiorina (1999) are networks of ties and groups through which people connect to one another and get drawn into community and political affairs. The first step was to identify and contact community organizations in the Harrisonburg area. Identification and contact with civic organizations was facilitated by the Fairfield Mediation Center and assisted by student researchers who were compensated with one-hour of course credit. The research team then called the contact person for each group (in the case of the organizations) to solicit participation, following up this request with a letter. Participation was explained to the participants as representing an opportunity to have a dialog about identity and attitudes related to migration and changing demographics in the Shenandoah Valley, and it was explained that an academic team would moderate each of these thematic conversations, taking place either in the form of a focus group or interview. The entirety of the dialog was recorded, transcribed into text, and then coded using Nvivo software for qualitative data analysis. The tool of analysis is a directed content approach, which imposes more structure than a traditional content analysis (Hsieh and Shannon 2005). In a directed content analysis, existing theory is used to develop coding categories from concepts or theories. In this case, I started out with three categories derived from the literature: (1) ethnoculaturalism (2) civic republicanism; and (3) civic political identity. The theory is also important in determining "operational definitions" for these categories that will guide the coding process (Hsieh and Shannon 2005). The theory guides the initial analysis, but other categories may emerge; in this study, family values and traditionalism are concepts of identity that emerged from the data analysis and will be discussed in the results section. 


\subsection{Group Selection}

To identify focus groups and individuals for the study, organizations that are noted in the literature as central to building a complete community, which may include churches, social service groups, and political advocacy groups. We have two goals for creating these groups: (1) to represent diverse interests or identity points in the community and (2) to create homogeneity within the groups to allow for those with similar characteristics to participate in a single session. Our concern is that comprising a group with highly diverse individuals may affect the quality of the data, as people may censor their ideas around those that differ greatly from them. The key to obtaining a cross section of views is to have multiple formats of inquiry on a related topic, and to have a diversity of groups that will participate. Groups were drawn from the Fairfield Center's key partnerships with diverse groups across civic, social, economic, and cultural sectors. This helped to ensure that the groups are representative of the population. It also allowed some pre-formed groups to participate, which will have the advantage of groups of people in each focus group that know each other and have a good history or working together. This may also help in the discussion of a sensitive topics such as identity and migration. In the case of organizations that were small or that could only send one or two representatives to participate, they were grouped with other participants from groups with similar mission statements to form a focus group or given the opportunity to participate in the project through an individual interview. For example, participants from New Bridges, Refugee Resettlement and Skyline Literacy all participated in a focus group together as did members of the Shenandoah Valley American-Filipino Group.

The mission statement and predominant activities of each group was evaluated to determine its primary purpose. Based upon this information, the groups were labeled as one of the following: (1) Social Service (2) Economic (3) Social-Civic (4) Economic (5) Education (6) Political/Advocacy (7) Government and Justice or (8) Church and Temple. Members of each group are represented in each of these categories in this project. These types of groups have been identified as important for coalition building at the local level and play a unique and important role in immigrant integration in other emerging and pre-emerging gateway cities (Singer 2008). Thus, determining the national and local identity of the members of these groups and how this shapes their attitudes towards immigration and related policies is an important step in determining how immigrants will be received in a pre-emerging gateway such as the Shenandoah Valley.

The sample ended up being very diverse both demographically and geographically. In terms of geographical representation, participants came from as far north as the Winchester area, and from as far South as the Roanoke area. The highest areas of representation in the sample are the Strasburg (northern Valley) and Harrisonburg (city/central valley) area, with other areas including Winchester, Woodstock, Strasburg, Elkton, Bridgewater, Mt. Jackson, Staunton and Roanoke. Demographically, most of the sample was employed, though there were two retirees and two full-time students included, and roughly an even number of men and women participated between the focus groups and individual interviews. A final note on the sample is that it is built from voluntary groups that are already active in the community and were self-selected to participate; the focus groups and interview questions did also contain primes and questions about identity and migration; thus, the salience of these issues may have been heightened among these groups, as well as the salience of political issues in general, as they knew that they were speaking to a political scientist.

\section{Empirical Analysis}

\subsection{Emergent Themes}

\section{Family Values and Traditionalism}

The idea of having of family values was a prominent theme in the interviews, but not necessarily in the political, moral, or even religious sense. Family values means making family the number one 
priority in life, spending quality time with family, and providing an atmosphere where one's family is safe and can flourish. As one participant put it, after growing up in the Valley and leaving to go to college in New York City, she was certain she wanted to return to the Valley to have her children. She remarked that while everything is there in NYC, getting to it is very difficult, and while the Valley is very boring, the quality of life is very attractive. Family values to her is a culture, she says.

"But, I think there is a general culture, of you know, it is family values-whatever that means. I'm afraid when I say that now that it means ultra-conservative and that's something I don't like. I mean something distinct from that, you know, there are parks, and activities, and good publics schools, and things that make it easier to raise families here. You know, sports programs and all of that.... I mean our proximity to Washington DC is very exciting to me. We can go in and see shows and concerts easily but here are people here who have never even been to Washington DC."

One woman described being from the Valley as "country" and "family-oriented." When I asked her to describe what she meant she said that people in the Valley are away from the hustle and bustle and they spend time together. She said family values means to her hardworking. And, then she followed up with putting families first, prioritizing family over money and power. She explains,

"I think that's probably one of the bigger things that I see (focus on the family). I was grown up country. You know they might not have the fanciest, biggest houses, but they have the most love in the house you would ever want to find."

She went on to talk about cookouts and activities like hunting being key to keeping the family together and about how she felt less safe as the city and surrounding areas continued to grow. She talked about how her grown son had gotten jumped coming home from visiting friends one night, something that she could not have imagined happening to her when she was his age (we had cousins to fear, not gangs, she joked). This concern about the changes that accompany growth is connected to family values. In the view of many Valley residents, change is already affecting the family because people no longer know who their neighbors are, hear stories about a rise in crime rates, and see families affected by parents having to commute to West Virginia and the Northern Virginia/DC area for jobs. Valley residents were used to knowing all of their neighbors and never having to worry about where their kids were, who they were with, and told stories of never having locked their doors. Several participants told me that they did not even know where the keys to their house or car were or what they even looked like. One participant recounted a story of having an alarm system that came with her house that she had never used ("I don't even know the code!") and another mentioned that a maintenance person locked the door behind him when finished with a job, and she could not get into the house for hours because she had no idea where her key was as she did not use it regularly. As one participant put it, "the Valley has to be brought forward because unfortunately DC is coming here and so are the gangs." Growth always brings change, and with the noticeable growth many residents were certain that the crime rates had increased. However, according to the Harrisonburg Police Department's Crime Statistics, crime rates across all areas have remained relatively stable since 2005 , showing no marked increase or decrease over the years. Thus, the growing concerns about safety in the community appear to be driven by residents feeling that they no longer know their neighbors and anecdotal incidents that are shared widely within the community when the occur.

In addition to safety concerns, the loss of manufacturing jobs has meant many parents now commute to West Virginia and Northern Virginia for work and some participants noted that this leaves less time for family gatherings and quality family time (although they do not directly blame immigration for the loss of jobs). But, they have resisted the expansion of the Valley on numerous occasions from infrastructure (the building of interstates and now the expanding of interstates), commerce (the building of shopping centers and businesses), schools, and even calling anything other than Harrisonburg an official city (all of the other areas are only townships). Geographically isolated by the mountains for much of the past, Valley residents learned to do things a certain way and when 
asked to explain why, they respond, "that is the way we have always done it." In every conversation and event, the role of tradition, and the idea of being resistant to change came up in some form. In one conversation participants discussed how change can be "scary" even though it is "normal" and talked about how because residents were used to being isolated in the past, they still live like they are today, even though that is no longer the case. Many have never been to Washington DC or the beach, even though both are only a few hours' drive away, for example. Although some may be hesitant about change, Harrisonburg is known as the "friendly city" and the Valley overall is very welcoming to newcomers. One participant who moved from Missouri noted that while people there were friendly, that people in the Valley "have a heart of gold" and have a quality beyond friendly that she could not describe. She said that she was drawn to the strong family orientation and even though she did not have any family in the Valley, her friendships were as strong as her familial bonds. However, a tension exists between wanting to keep things the way there have always been and the changing demographics that are now reshaping the face and character of the Valley.

\subsection{Apriori Themes}

\subsubsection{Ethnocultural Identity}

One of the most recurrent themes throughout the interviews was that being part of the "valley" meant that there was an emphasis on generations and ancestry. Most people who considered themselves or others as being "from" the Shenandoah Valley could trace several generations of their families back to living in the same town, perhaps even being part of the founding or settling of an area. As one participant noted, one characteristic that distinguishes the Shenandoah Valley from other rural Southern communities (with which it shares many characteristics) is that:

"the local history here is pretty well known. Typically, it's part of the family history. Six, seven, eight, nine, ten generations of the same family living, so they know great grandfather fought in the Civil War, and great-great-great-great grandfather came here in 1752 and he was from Germany. And they know all that stuff. And you don't find that in other places nearly as much and so local history is often treasured."

Another participant noted that, "you know entire families just by their last names."

There is a pride on having lived all or most of one's life in the Valley, and as one person put it to me, "it's an informal rule that you've got be here for 33 years before we accept you can tell us you are a Valley resident." What is interesting is that many were quick to embrace America as a country of immigrants and rejected ethnocultural identity at the national level but embraced it locally by defining it in terms of birth, ancestry, and extended residency in the Valley. One of the interviewees noted that families staying in the Valley for multiple generations makes it "a bit different' from other places in America. Another participant moved to the Valley because he wanted to be rooted after "running from New York to Miami to DC" and "wanted to slow it down." But he remarked:

"And, it's hard. It was very hard for my daughter because she came here as a junior-to get in. It was extremely difficult for her to incorporate herself into the community because she was seen as an outsider. It very difficult for her. It was times like, "Dad, I hate it here." I mean now she's fine and she's better after a year and half, doing athletics and sports and kind of forcing her way in. But for a long time, she was miserable, absolutely miserable."

These facets of ethnocultural identity are very prominent and heavily embraced, but the context is important. Ideas of ethnoculturalism, as expressed in the interviews, focus groups and informal conversations, are not explicitly rooted in racism or exclusion. They are the result of pride in the family and an emphasis on the ability to trace your ancestry many generations back, some even to the founding of the United States. For example, one participant's family could trace their origins back to Pocahontas and had artifacts and documentation that was on display in their home. However, even though not explicitly based on race, it appears that a higher ethnocultural identity can still lead to more exclusionary attitudes to migrants, both domestic and international. 


\subsubsection{Civic Political Identity}

References to Civic political identity often came up in the form of citizenship, philosophical principles, and patriotism. For example, one participant noted that the common element amid so much diversity among races of different people who live in America and among the diversity of micro-cultures found in the individual states is citizenship. He also said that citizenship implies principles such as equal treatment for all and rule of law. Another participant also noted that the cultures of the states are so different that it may be difficult to define what assimilation actually means; he described growing up in an environment where bilingualism was so engrained in the culture that it was frequent and second-nature; yet in other parts of the country it is seems to be controversial to speak in multiple languages. He describes in Virginia shopping with his wife, who although Hispanic, has light hair and light eyes, who would speak to him in Spanish in the store, and he would respond in English just so that people around him would not question whether he could speak English, something he would not have done in his home state. He explains,

"But, sincerely wanting to know and I think it's hard for people to delineate whether it's a philosophical coming overtime or whether it is these ideas we have been taught about differences in races, ethnicities, and languages. But for me I had the luxury of growing up where those things weren't as stark in instances- my family contacts only grew up speaking English but had enough Spanish around me that it was normalized to be bilingual in a sense where I grew up, as opposed to here for a lot of our kids and a lot of our families, it is not normalized to be bilingual, it's either in some way feeling they have to choose in some way very often or in some ways where there is such a stark contrast between the two cultures; whereas where I grew up in was one in the same. My grandfather could go off in Spanish and then he could go off in English, I mean it was kind of just the same back and forth. The things that we celebrated and the things my neighbors celebrated together became a part of our understood culture because this idea that we have one American culture and American identity, for me, seems like nothing further than the truth. When people say that well you know "they" need to assimilate, meaning people from other countries need to assimilate, well you know what do you mean? The American culture of the state of Oklahoma is very different from the American culture in Rhode Island or Maine or Chicago or California or Oregon or Montana, you know and each of those places have their own interpretation of what being American and what American culture is. One of the things they have in common is the philosophical American values and that's always been an area of focus on how we view American culture, because I see myself as American, I do not see myself as Mexican, I do not see myself as Latin American at all, not even a little bit. I use the word Mexican American a lot, I use the word Chicano a lot, I use the word Latino, but those are all very American ideas. They are not Mexican ideas, they know about Chicanos in Mexico but they are not Mexican ideas."

Patriotism at the local level was expressed as pride in the beauty of Shenandoah Valley, particularly regarding its natural beauty. Most people mentioned the Shenandoah National Park, the beauty of their surroundings, and the rural landscape. For many people what the Valley lacked in excitement or culture, the natural beauty and clean environment made up for. But, interestingly all demographic groups seemed to indicate difficult expressing being "proud" of their own group, whether they identified with their ethnic group, as a Valley resident, or as an American. For example, two white male participants described the change in American culture this way as part of a discussion that started on the topic of the decline of hunters:

"Well it's almost made comedic now. Something as patriotic as a gun, or somebody feels (in Southern accent) "Merica." You know, "it's almost like putting it down. Like, oh you're proud to be an American. (southern accent) Merica. It's weird dynamic that as well, nobody wants to embrace, it's almost as if they've tied the term American to redneck ... to the old redneck. To the old KKK. Or somebody waving a rebel flag. Larry the Cable Guy. That's it. Yeah. Get er done. It's unfortunate. I strongly identify myself as an American and I'm proud of it. I always have been. It's kind of disappointing to 
see the direction that this nation is going in just about everything. I don't know how we let ourselves get to this point."

Another participant noted that there used to be some shame in talking about being from different parts of the Valley because some areas were "poor" but now it seems like "it's all of us against the city slickers and they think we are stupid. Well, why do they want to move down here then?" And, then there were the participants from immigrant families or those who knew of individuals from immigrant families that felt conflicted about their identities and whether they truly wanted American citizenship. The conversation is from one of the focus groups below:

Participant 3:

"Just some reflections real quick, I apologize if they seem scattered but one is that when I talk to members who are a part of the core dominant culture, for definition you could say white, but often when their attempting to frame things positive for immigrants-like when someone says oh they are just so happy to be here, they're so grateful for all the opportunities we give them, and oh they just can't wait to become Americans. There is an assumption that everyone who comes here wants to be an American and become a citizen and gain the American identity, especially right now with the immigration reform, but actually there are a lot of people who are saying "I don't want to be an American citizen ..."

Participant 8: Because of the pressure and the expectation ...

Participant 3:

Yes. A good friend of mine, his parents are here, and they have their legal residence but they are not ready to go ahead and change citizenship. And in my own grandfathers history, the family story is that when grandpa [[says name]] would cross the border, he would take his hat off and weep when he went back to Mexico because he missed it so much and I think that a lot of people don't understand, especially for Mexican immigrants and descendants of Mexican immigrants, our home territory and family land is right around the corner and so it's not like if you are coming from Sri Lanka or somewhere else where you hold that a little closer to your heart than you would physically, but when you can drive or fly back to some place you realize that tension that pushes you to the united states but the tension that also pulls you back to your own country. So, I think for a lot of Latin Americans, there are deeply conflicting identities and draws so as [[Rick]] was saying, and I can certainly attest to as a child who is Hispanic and I'm 40 years old now and I still feel like I have to qualify calling myself a Hispanic, even though I know that I am, but in the eyes of others, there are things you get from both sides of the fence/culture saying "oh well you're not a real Mexican" and "I'm like I never claimed to be a Mexican" or you know people doubt your credentials in terms of your family and who your family background are but then there is this other side there's this idea of "to turn white" and so among people from your core cultural background, they can levee a very brutal criticism that you've become "white." So, a lot of times mastering English or you know my father were so extremely proud of being able to speak Spanish without any noticeable accents, and while he was very proud of his Spanish speaking, he didn't pass it on to his kids. So, the United States, I don't know that we're are the only place where these ethnic identities are so jumbled but in terms of immigrants, its assumption that everyone wants to fit in and take on the shirt of the United States."

\subsubsection{Civic Republican Identity}

In the very beginning, residents noted some frustration with how the city of Harrisonburg handled the influx of immigrants, particularly in the school system. One father noted that it was not fair that English speaking students had to pass tests in Spanish while native Spanish speakers were exempt from tests. Although the school system today uses a rotation-based immersion schedule for all students, some parents said there were some growing pains in getting to this point. Today, 
anecdotal stories note the awareness in the surrounding small towns during apple harvesting season that locals generally do not run errands on Fridays because they find long lines of Hispanic men at the banks and the grocery stores. The civic-republican dimension expresses identity through engagement, participation, and listening. In Harrisonburg, through the University and through the city, listening cafes, both formal and informal are often organized and the willingness of residents regardless of political affiliation, was a common theme in the fieldwork. The idea is that there was clearly a segment of the community actively worked to promote an inclusive dialog, and to engage newcomers in the community despite the emphasis on nativism and traditionalism. As one participant explains,

\begin{abstract}
"Growing up here in the valley, I've had two kinds of disparate experiences, I grew up in Bridgewater just 10 min south of here, born and raised and live there now. I was born into an ultra-conservative family and through listening to the media and travelling within the states, I began to understand the Shenandoah valley was very conservative and as I sent my son away to college, away to Columbia, again hearing about how different we were from everyone else he met at VA Tech or everyone else he is experiencing abroad, and yet at the same time there seems to be in the valley also another side of greater sophistication where there is a tendency to make sense building and have more open eyes. I can see in myself, through education, through travel, that there has been a movement away from identifying with conservative, whatever that meant for us when I was young to something a little bit different, and somehow the Shenandoah valley is identified as ultra conservative to other parts of the country, and yet somehow something has evolved here of significant support and openness, which is something I'm very proud of. Now I get to talk to people about how receptive and responsive parts of the community are."
\end{abstract}

Another theme that surfaced in several conversations is the Mennonite influence in the community and their role in promoting peace and justice in the community:

"I think in a sense that's why we can be a little bit of a poster child of a community because maybe it's the influence from the universities or the Mennonite and peace background, but we do have a number of people with a leadership or voice and that although as you said may not belong to one group or the other, but are able to make these connections and express them and just create that little bit of a balance. It makes us have those moments of brightness that we all love and make us want to stay here."

Although nationally partisanship has become hyper-polarized, and this is also reflected in voting trends in the Shenandoah Valley, there is a healthy amount of dialog between different ideological groups regarding political issues; the community is very engaged with all types of events taking place regularly such as listening cafes that brings together inter-faith communities, cultural festivals such as the International Festivals, events sponsored through the local universities including James Madison and Eastern Mennonite and a number of organized political protests. As with any community, conflict does arise, but groups often do talk to those with opposing views. They often try to understand opposing viewpoints as well. For example, one Hispanic participant noted that he sought advice from a local resident about the symbolism of the Confederate flag after hearing that a student got suspended from school for bringing it on the campus. He wanted to understand why it was an important symbol to some local residents and also to understand why it was so threatening that the school would react in such a way to punish the student. Another participant also said that she wanted to learn more about local history when she learned that many residents has been forcibly removed to create the Shenandoah National Park. She said she understood how that could make residents skeptical of the federal government. Below is an example from a participant who was invited to speak to the Tea Party, a group that he did not share views with politically:

"We had a group called the Minute Men who had this VA chapter of the Minute Men and the present-day formation of the Minute Men is those who started in Arizona with protecting the borders and keeping those from crossing the border. So, there is a VA chapter in Herndon and some one out of Waynesboro invited them to come speak in Harrisonburg and had a rally. Basically, the goal was a 
rally and sort of anti-immigrant rhetoric, and 3/4ths of the audience there were pro-immigrant. And, I was actually invited to speak at the event (to their credit the minute men invited me to speak). But to me it emphasized that the anti-immigrant rhetoric is not consistent with the values of the Shenandoah Valley. It's not consistent with who the valley is and when the valley has come, and who they express themselves to be. The least common denominator sometimes becomes the spokesperson for groups, but you know they happen to be loud. The loudest is the least common denominator, so because their voice is louder, they adopt themselves as the spokespeople. For example, the same could be said with the TEA party, you know when I look at some of their core beliefs, I don't agree but I can understand them but then the rhetoric that comes out because of the vocal least common denominator really changes the nature of our conversation. The simple fact that we don't have an immigration debate in this country anywhere, we have one side doing their press rallies and conferences and then the other side has their press rallies and conferences and then they speak to each other through the media. They don't actually ever sit down and have a real conversation with each other. So, that has always been a real strong underlying point when we talk about the macro level of immigration in the US and then use the Shenandoah Valley as a micro causal. All the things that talk about, the fears of what immigration is bringing, in their minds to our country, is not true in the Shenandoah Valley. When I give presentations about immigration, what I first do is I suspend political correctness (give them permission to not be politically correct), most of you would probably cringe at my presentations, but these are poised for conservatives who have not been exposed to these issues, to talk with their jargon. I have them list all perceived stereotypical problems of immigration and illegal immigration, so we write them all down on the board. Then one by one we can go through those and say well actually this isn't relevant or true in the Shenandoah Valley. This isn't what is happening here, actually the real percentages are this and that and this. So just by doing this I think it has been a great way to use as a poster child for talking about immigration in this country."

Joe, a transplant from Northern Virginia, agrees that is difficult to come in as an outsider, but agrees that engagement and mindset are the keys to acceptance. He says that you must learn to accept that the Valley is a very traditional, conservative place, and that "if you are on a different page personally, you can't let that rule your life or you won't be happy here." His advice to someone who moves to the Valley from another place is to "be part of the culture" and "make a connection." He says that you might join a church or an organization, something that will give you a social network that connects you with the natives, and then they are very willing to embrace newcomers. For him personally, he has joined historical societies and museums. Another example if the Shenandoah Valley Filipino Group, initially formed by a retired school teacher who had lived in the Valley for almost 20 years and a recent arrival from Missouri who wanted to find connections with other residents. The group now has over 50 members and hosts several events each year that are open to the public, in addition to performing at the local schools and at the International Festival.

To be clear, there is not perfect harmony at all times in the Shenandoah Valley. Harrisonburg has made the national news at least twice recently with two stories, one which went viral on Facebook. When the mosque in Harrisonburg was vandalized with graffiti, the community came together with an inter-faith event called "We are Harrisonburg" at the Mosque. At Jess' Quick Lunch downtown, a server was not given a tip because the couple she serviced thought that she was an illegal immigrant and left a handwritten note on the check saying, "we only tip citizens," even though the server was a Native-born Hispanic woman who had lived in Harrisonburg her entire life. The resistance to change, strong generational identity, and the concern over how the growing population will impact family values are present but are balanced by a strong civic republican identity that encourages an active community that listens and engages it members. The community gives different members opportunities to express their cultural heritage whether it be through the International Festival, Civil War Reenactments, Listening Cafes and various Natural and Historical Societies. While the civic-republican conception of identity can be found throughout the Valley, it seems to be most actively cultivated and the most prevalent in the city of Harrisonburg itself, and does seem to facilitate more 
positive views towards immigrants. There is also a visible political divide in the voting patterns of the past few presidential elections, including the election of 2016, where the city of Harrisonburg voted in the majority for the Democratic candidate, while the surrounding counties voted in the majority for the Republican candidate. Although the driving factors for this recent change in Harrisonburg city are beyond the scope of this paper, potential explanations include the changing demographics and the fact that James Madison University is in Harrisonburg has contributed to the shift in voting behavior. As Harrisonburg expands and continues to grow, the fact that the more "urban" area in the Valley voted for Hillary Clinton, and the surrounding rural areas voted for President Donald Trump, follows the larger patterns of the differences in rural vs. urban voting across the country as well.

Then Candidate Trump's message regarding immigration tapped into a number of concerns articulated in the data, such as anxiety that accompanies rapid population growth, and identity concerns that have not been traditionally captured by mainstream identity politics (for example, the pride that white residents feel in their history and their generational ties to this place and wanting to take pride in an "American" identity without feeling any sense of shame of being mocked by others). However, his message regarding refugees did not resonate very widely in the Shenandoah Valley, as there is a long history of refugee resettlement that is quite visible and viewed positively within the community. While there may be a tendency to characterize "Trump" voters as anti-immigrant, I would argue that this dichotomy is too simplified to capture the complexities of the various attitudes expressed at the local level. This research represents an exploration of local responses to significant population changes within a community, and a nuanced qualitative approach is necessary to tease out the relationship between identity and attitudes towards immigrants, particularly in these newer gateway regions.

The dichotomy of civic versus ethnic identity that has been the cornerstone of much of the work on immigration utilizing survey data and large $\mathrm{N}$ studies holds valuable explanatory power when it comes to the local level, but also problematizes how we as social scientists approach the concept of "American" identity. A culture of traditionalism and a distinct conception of family values are important conceptions of identity among Valley residents, and these dimensions are not picked up as easily by the survey questions that are generally associated with the ethnic and civic framework. Yet, they are important factors of local and national identity in the Shenandoah Valley, and concerns about how the most fundamental aspects of life, including the quality of parks, schools, and neighborhoods have an influence on attitudes towards newcomers. The friendliness and openness of the local culture is at odds with the desire to have a "small town" atmosphere where everyone knows everyone. The traditionalism embedded in the local culture is sometimes in conflict with the nature of migration as it brings new people, idea, and inevitably, ways of doing things, to places over time.

At the local level, individual ethnocultural identity places more emphasis on ancestry and place of birth than an identity that is explicitly tied to race or religion. Heritage and generational identity are key components of individual and local identity in the Shenandoah Valley. In traditional large N studies that create scales from surveys, this nuance may be lost. Individuals may receive a high score on this dimension of identity, but it may be because the sense of place and ancestry are ranked so highly. The ethnocultural dimension is quite prominent in the Shenandoah Valley, but it is also balanced by the two civic dimensions, which also have a place in defining identity. An in-depth study at the local level also sheds some light on why the civic political dimension might sometimes have positive and negative empirical effects on attitudes towards immigrants. There were different views of the value of citizenship and patriotism, and not all views were positive or supportive of these as defining elements of identity. Many individuals expressed fear or insecurity about their identity and how they would be perceived by others, and did not feel confident expressing pride in their group, whether it be an ethnic group or a broader American identity. There were also mixed feelings about American citizenship as a positive marker of American identity. Using a more granular qualitative approach, it becomes clear why the civic political dimension has had mixed empirical results in previous studies. However, 
the civic republican dimension performed largely as expected, and serves as an important temper to the more cautious, even at times exclusionary, views that can be fostered by the ethnocultural and civic political dimensions of identity.

\section{Conclusions}

This study qualitatively explores the content of identity in the Shenandoah Valley, and examines whether this identity is compatible with a traditional ethnic versus civic framework of national identity. The findings show that these frameworks of identity do have explanatory power at the local level but provide an incomplete picture. Thus, I conclude that a qualitative case study on rural areas with rapidly changing demographics can add some value to our current understanding of the relationship between identity and attitudes.

Some limitations of this study are that it relies only on interviews, focus groups, and group events, but does not include a comprehensive content analysis of local media and social networks, which may give a more complete picture of local identity and attitudes. The inclusion of more community-focused statistics and current public opinion polls can also provide useful context and serve as a starting point for future research design. Focus groups and interviews provide very rich data that can be analyzed in-depth, but they only represent a few voices in a very large community that stretches across the entire Western part of Virginia. Finally, future research should incorporate a more nuanced analysis that looks at attitudes towards different groups of migrants (are attitudes more favorable towards domestic migrants than immigrants, for example) and across different groups of immigrants, including by region (Latin America vs. Asia), and across countries (are attitudes more favorable towards Congolese refugees than Iraqi refugees).

Acknowledgments: The author would like to thank the James Madison University College of Arts and Letters for funding the research. The author would also like to thank the students who contributed to the project including Sarah Burke, Erica Chavez, Kelly Dayritt, Brandon Ford, Kaitlyn Myers and Peyton Kesee.

Conflicts of Interest: The authors declare no conflict of interest.

\section{References}

Banning, Lance. 1986. Jeffersonian Ideology Revisited: Liberal and Classical Ideas in The New American Republic. William and Mary Quarterly 43: 3-19. [CrossRef]

Bearinger, David. 2014. The Changing Face of Virginia: Immigration and the Humanities. Report Prepared for Virginia Humanities. Available online: https:/ / www.virginiahumanities.org/2014/10/the-changing-faceof-virginia-immigration-and-the-humanities/ (accessed on 24 April 2018).

Berube, Alan D. 2017. These Communities Have a Lot at Stake in Trumps' Executive Order on Immigration. Washington: The Brookings Institution, January 30.

Brubaker, Rogers. 2004. Ethnicities without Groups. Cambridge: Cambridge University Press.

Byrne, Jennifer, and Gregory C. Dixon. 2016. Just Not Like Us: The Interactive Impact of Dimensions of Identity and Race in Attitudes towards Immigration. Social Sciences 5: 59. [CrossRef]

Byrne, Jennifer. 2011. National Identity and Attitudes towards Immigrants in a "Multicreedal" America. Politics and Policy 39: 485-514. [CrossRef]

Citrin, Jack, Cara Wong, and Brian Duff. 2001. The Meaning of American National Identity: Pattenrs of Ethnic Conflict and Consensus. In Social Identity, Group Conflict and Conflict Resolution. Edited by Jussim Ashmore and Wilder. New York: Oxford University Press.

Citrin, Jack, and Brian Duff. 2001. The Meaning of American National Identity: Patterns of Ethic Conflict and Consensus. In Social Identity, Inter-Group Conflict, and Conflict Resolution. Edited by Richard D. Ashmore, Lee Jussim and David Wilder. New York: Oxford University Press.

Cramer-Walsh. 2012. Putting Inequality in its Place: Rural Consciousness and the Power of Perspective. American Political Science Review 106: 517-532.

Davis, Darren W., and Brian D. Silver. 2004. Civil Liberties versus Security: Public Opinion in the Context of the Terrorist Attacks on America. American Journal of Political Science 48: 28-46. [CrossRef] 
De Figueiredo, Rui J. P., Jr., and Zachary Elkins. 2003. Are Patriots Bigots? An Inquiry into the Vices of In-group Pride. American Journal of Political 47: 171-88. [CrossRef]

Gerstle, G. 2001. American Crucible: Race and Nation in the Twentieth Century. Princeton, NJ: Princeton University Press. Heath, Anthony F., and James R. Tilley. 2005. British National Identity and Attitudes towards Immigration. International Journal on Multicultural Societies 7: 119-32.

Hjerm, Mikael. 1998. National Identities, National Pride and Xenophobia: A Comparison of Four Western Countries. Acta Sociologica 41: 335-47. [CrossRef]

Hjerm, Mikael. 2004. Defending Liberal Nationalism-At What Cost? Journal of Ethnic and Migration Studies 30: 41-57. [CrossRef]

Higham, John. 1988. Strangers in the Land: Patterns of American Nativism: 1860-1925. New Brunswick: Rutgers University Press.

Hochschild, Arlie. 2016. Strangers in Their Own Land: The Making and Mourning of the American Right. New York: The New Press.

Hsieh, Hsiu-Fang, and Sarah E. Shannon. 2005. Three Approaches to Qualitative Analysis. Qualitative Health Research 15: 1277-88. [CrossRef] [PubMed]

Huntington, Samuel P. 1981. American Politics: The Promise of Disharmony. Cambridge: Belknap Press.

Jensen, Lief. 2006. New Immigrant Settlements in Rural America: Problems, Prospects and Policies. Durham: University of New Hampshire.

Jones, Frank L., and Philip Smith. 2001a. Diversity and Community in National Identities: An Explanatory Analysis of a Cross-National Patterns. Journal of Sociology 37: 45-63. [CrossRef]

Jones, Frank L., and Philip Smith. 2001b. Individual and Societal Bases of National Identity: A Comparative Multi-Level Analysis. European Sociological Review 17: 103-18. [CrossRef]

Kinder, Donald R., and Cindy D. Kam. 2010. Us against Them: Ethnocentric Foundations of American Public Opinion. Chicago: University of Chicago Press.

Krogstad, Jens Manual, and Michael Keegan. 2014. 15 States with the Highest Share of Immigrants in Their Population. Washington: Pew Hispanic Center, May 14, Available online: http:/ /www.pewresearch.org/fact-tank/2014/ 05/14/15-states-with-the-highest-share-of-immigrants-in-their-population/ (accessed on 23 April 2018).

Lewin-Epstein, Noah, and Asaf Levanon. 2005. National Identity and Xenophobia in an Ethnically Divided Society. International Journal on Multicultural Societies 7: 90-118.

Lichtblau, Eric. 2003. Bush Issues Racial Profiling Ban but Exempts Security Iniquiries. New York Times, June 18, A1.

Malkin, Michelle. 2004. Racial Profiling: A Matter of Survival. USA Today, August 17, 13A.

Miller, David. 2000. Citizenship and National Identity. Cambridge: Polity Press.

Morse, Ann, and Brian K. Ray. 2008. Building the New American Community: Newcomer Integration and Inclusion Experiences in Non-Traditional Gateway Cities. Washington: Migration Policy Institute.

Perrine, Andrew D. 2017. How One Small Town in Virginia Embraces Immigration-And is the Better off for It. The Washington Post, February 10.

Pickus, Noah M. Jeddiah, ed. 1998. To Make Natural: Creating Citizens for the 21st Century. In Immigration and Citizenship in the 21st Century. Lanham: Rowman and Littlefield.

Price, Marie, and Lisa Benton-Short. 2007. Counting Immigrants in cities Across the Globe. Migration Information Source, January 1.

Roshwald, Aviel. 2006. The Endurance of Nationalism: Ancient Roots and Modern Dilemmas. Cambridge: Cambridge University Press.

Salins, Peter D. 1998. Assimilation: American Style. New York: Basic Books.

Schildkraut, Deborah J. 2002. The More Things Change: The More They Stay the Same: American Identity and Mass and Elite Responses to 9/11. Political Psychology 23: 511-35. [CrossRef]

Schildkraut, Deborah J. 2003. American Identity and Attitudes toward Official-English Policies. Political Psychology 24: 469-99. [CrossRef]

Schildkraut, Deborah Jill. 2005. Press One for English: Language Policy, Public Opinion and American Identity. Princeton: Princeton University Press.

Schildkraut, Deborah J. 2007. Defining American Identity in the 21st Century: How Much There is there? Journal of Politics 69: 597-615. [CrossRef]

Schildkraut, Deborah J. 2009. The Dynamics of Public Opinion on Ethnic Profiling After 9/11: Results from a Survey Experiment. American Behavioral Scientist 53: 61-79. [CrossRef] 
Schildkraut, Deborah J. 2011. Americanism in the 21st Century: Public Opinion in the Age of Immigration. Cambridge: Cambridge University Press.

Skocpol, Theda, and Morris P. Fiorina. 1999. Making Sense of the Civic Engagement Debate. In Civic Engagement in American Democracy. Edited by Theda Skocpol and Morris P. Fiorina. Washington: The Brookings Institution Press and the Russell Sage Foundation, pp. 1-23.

Singer, Audrey, Susan W. Hardwick, and Caroline B. Brettell. 2008. Twenty-First Century Gateways: Immigrants in Suburban America. Migration Information Source, April 30.

Singer, Audrey. 2008. Reforming U.S Immigration Policy: Open New Pathways for Integration. Opportunity 08: A Brookings Institution Project; Washington: Brookings Institution.

Smith, Rogers M. 1988. The Limits of Liberal Citizenship. The Western Political Quarterly 41: 225-51. [CrossRef]

Smith, Rogers M. 1997. Civic Ideals: Conflicting Versions of Citizenship in U.S. History. New Haven: Yale University Press.

Stepler, Renee, and Mark Hugo-Lopez. 2016. Ranking the Latino Population in the States. Washington: Pew Hispanic Center, September 8, Available online: http:/ / www.pewhispanic.org/2016/09/08/4-ranking-the-latinopopulation-in-the-states/ (accessed on 23 April 2018).

Wilcox, Shelley. 2004. Culture, National Identity, and Admission to Citizenship. Social Theory and Practice 30: 559-82. [CrossRef]

Zarrugh, Laura. 2007. From Workers to Owners: Latino Entrepreneuership in Harrisonburg, VA. Human Organization 66: 240-48. [CrossRef]

Zarrugh, Laura. 2008. The Latinization of the Central Shenandoah Valley. International Migration 46: 19-58. [CrossRef]

(C) 2018 by the author. Licensee MDPI, Basel, Switzerland. This article is an open access article distributed under the terms and conditions of the Creative Commons Attribution (CC BY) license (http:/ / creativecommons.org/licenses/by/4.0/). 